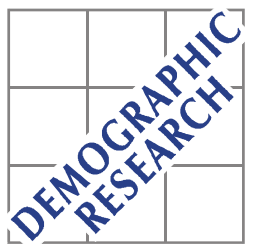

Demographic Research a free, expedited, online journal of peer-reviewed research and commentary in the population sciences published by the Max Planck Institute for Demographic Research Konrad-Zuse Str. 1, D-18057 Rostock · GERMANY www.demographic-research.org

DEMOGRAPHIC RESEARCH

VOLUME 14, ARTICLE 19, PAGES 453-484

PUBLISHED 30 MAY 2006

http://www.demographic-research.org/Volumes/Vol14/19/

DOI: 10.4054/DemRes.2006.14.19

Research Article

Interdependence between sexual debut and church attendance in Italy

Marcantonio Caltabiano

Gianpiero Dalla Zuanna

Alessandro Rosina

(C) 2006 Max-Planck-Gesellschaft. 


\section{Table of Contents}

1 Introduction $\quad 454$

$2 \quad$ Religion and sex among Italian young people 456

2.1 Religion 456

2.2 Sex 458

$2.3 \quad$ Religion and sexual behaviour and attitudes $\quad 459$

$3 \quad$ Hypotheses and methodology $\quad 461$

$4 \quad$ Data and variables $\quad 464$

4.1 Data 464

$\begin{array}{lll}4.2 & \text { Variables } & 467\end{array}$

5 Results 469

$\begin{array}{lll}6 & \text { Conclusions and discussion } & 471\end{array}$

$\begin{array}{ll}\text { References } & 473\end{array}$

$\begin{array}{ll}\text { Appendix } & 478\end{array}$ 


\title{
Interdependence between sexual debut and church attendance in Italy
}

\author{
Marcantonio Caltabiano ${ }^{1}$ \\ Gianpiero Dalla Zuanna ${ }^{2}$
}

Alessandro Rosina ${ }^{3}$

\begin{abstract}
The influence of religion on an individual's life-course in general - and on sexual behaviour in particular - has long been recognised by social scientists, although few studies have explored the reciprocal causal interdependence between religiosity and sexual debut, mainly in an overwhelmingly Catholic European context. In this paper, we study the dynamic bi-directional effect between first coital experience and discontinuance of church attendance among a representative sample of Italian students. Both effects work, contrasting the results of other authors regarding the USA, where only the effect of religion on sex has been detected. The present results do not change when the two processes are considered simultaneously and unobserved heterogeneity is taken into account. Some possible explanations are discussed.
\end{abstract}

Department of Statistical Sciences, University of Padova, Via C. Battisti 241, 35121 Padova, Italy. E-mail: mcalt@stat.unipd.it; (Tel. +39.049.8274192; Fax +39.049.8274170)

Department of Statistical Sciences, University of Padova, Via C. Battisti 241, 35121 Padova, Italy.

Institute of Population and Geographical Studies, Catholic University of Milan, Largo Gemelli 1, 20123 Milano, Italy. 


\section{Introduction}

Catholicism shares with other religions an explicit desire to regulate sexual, marital and reproductive (SMR) behaviour. This is seen mainly in articulated, explicit norms which are intended to guide and unify the behaviour of its followers. The most important and well-grounded rules concern sexual intercourse exclusively within marriage, a ban on birth control practices not based on abstinence, and the indissolubility of marriage. The individual and collective importance of these prescriptions make this normative system reciprocal, at least formally: on one hand, such exacting norms strongly direct behaviour; on the other, that behaviour is so clearly recognisable and important in an individual's life that it defines a clear boundary between those who adopts the norms and follow the Church's precepts - and those who disregard them, placing themselves outside it.

Yet the existence of explicit norms is a necessary condition, albeit not a sufficient one, to guarantee close reciprocity between following the precepts of a religion and respect for its prescriptions regarding SMR behaviour and attitudes. This reciprocity needs to be perceived both at individual and collective levels, and there must be institutions which are capable of reinforcing it and making followers comply with it (Goldscheider, 1971; McQuillan, 2004). If these conditions are not in place, on one hand the norms cannot influence the actual behaviour of followers; on the other, those who do not respect them may continue to feel close to this religion, and to recognise themselves as in communion with it. ${ }^{4}$

This last situation now characterises almost everywhere the relation between affiliation to the Catholic Church and obedience to its moral prescriptions on SMR behaviour. More generally - enlarging the specific context to family and sexual ethics we may speak of "religious bricolage", or patchwork religion (Luckmann, 1979; for Italy, see Garelli et al., 2003; Trombetta, 2004), referred to the majority of people who maintain a relation with the transcendent, "create" an individual sense of religiosity, and accept or refuse specific beliefs, precepts and rituals proposed by one religion (or more than one). The consistency, with reference to a corpus of prescribed norms, is replaced by the desire to satisfy one own's specific need for a relationship with God and/or the religious institution. This individually defined religion becomes one of the items in the

\footnotetext{
${ }^{4}$ These aspects have been thoroughly studied in relation to control of marital fertility. Where a strong institutional and individualising presence of the Catholic Church exists, control of individual behaviour - and hence of SMR behaviour - is set in place through a system of rewards and sanctions which essentially involves all the institutions with which each individual interacts: from family to neighbours, from parish to school, from the clergy to civilian authorities (such as doctors and midwives). This is what happened, for example, in Ireland and Québec in the 19th and early 20th centuries (Ò Grada, 1991; Gervais and Gauvreau, 2003). In such social contexts, religious affiliation contributed to slowing fertility decline, whereas lack of affiliation to the teaching of the Church on SMR behaviour coincided with religious exclusion (and often part exclusion from the local community). Yet, the case of Québec and Ireland is quite peculiar: for centuries the Catholic Church has been the heart of national and local identity for two countries colonised by foreigners affiliated to another religion. However, generally speaking, the close reciprocity between following a religion and respect for its prescriptions on SMR behaviour has been less stringent: the norms have not always been rigorously applied, and those who behaved in a different way were not always completely excluded at religious and social levels.
} 
"scale of values" which direct the preferences of citizens of the post-modern world, also with specific reference to SMR behaviour (Hakim, 2003; van de Kaa, 2004). This happens in a highly secularized context, where the Church has only limited power to "oblige" individuals to conform to its norms.

Yet, even in such a deconstructed context, the reciprocal influence of religion and SMR behaviour and attitudes has not withered away. As regards some aspects, it seems to have almost vanished. Commenting on the rapid convergence of sexual behaviour and contraception of American Catholics towards the average national behaviour, Westoff and Jones (1979) speak of "the end of Catholic fertility" (see also Brewster et al., 1998, for US adolescents, and Okun, 2000, for Israeli women). For other aspects, the reciprocal tie continues to be complex and strong, as Thornton et al. (1992) have shown, for example, for cohabitation and marriage in the USA. As a consequence, even in post-modern social contexts which are largely secularised, to better understand some important aspects of SMR behaviour and attitudes, their interconnections with religious behaviour should be considered.

In this paper, we examine whether the age at sexual debut and the age at ceasing regular church attendance are interrelated for young Italian students, by means of data from a national survey collected during 2000-2002. Obviously, this analysis is not exhaustive in terms of the complexity of possible connections between religiosity and SMR behaviour and attitudes in the diverse contexts of the post-modern world. However, it is useful for four main reasons.

First, we chose two fields which have a long tradition of empirical measurement. Therefore, drastic simplification - using only these two indicators of religiosity and sexual behaviour - is compensated by awareness of having to deal with measures easily comparable in time and space. Second, we are able to compare Italy with the USA, the only country where this specific topic has been thoroughly studied (Thornton and Camburn, 1989; Hardy and Raffaelli, 2003; Meier, 2003; Rostosky et al., 2003, see part 3). Third, since in Italy - until recently - the overwhelming majority of Italian people was baptised, and received a specific Catholic education and the Holy Sacraments (see following section), our findings on individual behaviour may be interpreted with reference to a clear-cut institutional context. Lastly, the sample survey on Sexuality of Italian Students (SIS) was constructed with the aim of explaining early sexual behaviour, reconstructing some processes which may, in theory, be connected with sex. Consequently, for each of our students, the history of sexual debut may be compared with the history of church attendance. 


\section{Religion and sex among Italian young people}

\subsection{Religion}

Most young Italians who are 20 years old today were christened in the Catholic Church soon after birth; they received Reconciliation and Communion at the age of 8-10 and Confirmation at 14-15. These moments - particularly Baptism and First Communion have often been important rites of passage, emphasised by preliminary religious teaching (for parents as regards Baptism), involving gifts and family celebrations. During childhood and pre-adolescence (6-14), most 20-years-old attended catechism classes, out of school hours.

Most Italian young people, although they attended state schools, also had Catholic religion classes at secondary school (for about one hour a week). These classes are held by teachers directly chosen by the Church (see table 1, indicator [1]). If pupils decide not to attend the religion class, they have one hour less of schooling a week, but this does not have any particular consequence on their school assessment. Consequently, it is a matter of choice rather than constriction. In addition, in 2000 most first marriages were celebrated according to Catholic rites, ratified by a specific agreement between the Italian State and the Catholic Church in 1929, and renewed in 1984. The bride and groom pronounce their vows before a priest during the wedding ceremony, in which they usually receive Holy Communion as well. In Italy, this "agreed rite" also has civic value. This means that the rite need not be repeated before a state official, as occurs in other mainly Catholic countries, e.g., France (see table 1, indicator [2]).

The religious education of the young people - one of the greatest pastoral efforts of the Italian Catholic Church in the last few decades - has shown clear signs of strain in recent years. As the previous two indicators show, although the vast majority of young Catholics still follow initiation into the sacraments and catechism, slow erosion may be observed, which is becoming much more marked, especially in the larger cities in the north and in regions (e.g., Emilia-Romagna, Tuscany and Umbria) where, during the second half of the 20th century, the sub-culture of left-wing political parties prevailed, under the direction of the Italian Communist Party (Cesareo et al., 1995).

In spite of these changes, in Italy one can still speak of mass religious socialisation during childhood and pre-adolescence. The popular choice of a religious marriage points to a very common persistence of attitudes and behaviours which are close to religious precepts. However, in many cases this choice seems to be more a tribute to tradition, habits and parents' wishes, rather than to be the conscious consequence of

\footnotetext{
${ }^{5}$ The relationship with religion of young foreigners living in Italy - who are now quite numerous especially in the centre and north - is obviously very different and strongly influenced by the tradition of their original countries. According to 2002 estimates, $24 \%$ are Catholic immigrants, $21 \%$ Christian (mostly Orthodox), 37\% Muslims; 18\% belong to other religions or have no religion (Caritas Italiana, 2003).
} 
well-defined religious choices. Indeed, other indicators show that most young people move away from the Church and religion during adolescence (see table 1, indicators [3]-[5]), although the proportion of self-declared religious young people is much higher than elsewhere in Western Europe (see notes under table 1). Moreover, it is incorrect to imagine of a progressive, inexorable decline. Indicators show that this position has not matured over the past years, but that it was already in place in the early 1980s (thus, for young people who were born in the late 1950s). Previous surveys show that the moving away of young Italian people from religious practices goes back to the 1960s and early 1970s (Cesareo et al., 1995, 73-79). Instead, the past 30 years have been characterised by a steady return (Pisati, 2000).

In conclusion, during the period 1970-2000, the relationship of young people with the Church became stable in Italy, taking on the following two features: (1) religious socialisation and mass initiation in the sacraments during childhood and preadolescence; (2) progressive moving away of most young people from religious practices during adolescence and young adulthood.

Table 1: Some indicators of religiosity in Italian young people and "Catholic religion supply" in Italy

\begin{tabular}{|c|c|c|c|c|c|}
\hline & 1983 & 1987 & 1992 & 1996 & 2000 \\
\hline $\begin{array}{l}\text { [1] Proportion of high school students (aged 14-18) } \\
\text { attending optional religion course at state schools }\end{array}$ & --- & --- & 89 & 88 & 88 \\
\hline [2] Proportion of civic first marriages & 11 & 12 & 13 & 14 & 15 \\
\hline $\begin{array}{l}\text { [3] "Religion is important in my life" (much or very } \\
\text { much) }\left(^{*}\right)\end{array}$ & 26.9 & 31.5 & 33.9 & 35.8 & 30.6 \\
\hline [4] Church attendance (at least once a month) & 36.4 & 37.5 & 35.9 & 36.2 & 33.3 \\
\hline $\begin{array}{l}\text { [5] "Active participation in religious activities is very } \\
\text { important in my life" }\end{array}$ & 12.2 & 12.7 & 13.6 & 14.1 & 11.3 \\
\hline
\end{tabular}

$\left({ }^{*}\right)$ The same proportions for people aged 18-24 of other countries interviewed in 1993 were as the follows: $5 \%$ Japan; $37 \%$ USA; 9\% UK; 5\% Germany; 7\% France; 6\% Sweden; 16\% Russia (YAA, 1993).

Sources:

Indicator [1]: Osservatorio Socio-Religioso del Triveneto, several years.

Indicator [2]: Barbagli et al. (2004), p. 131

Indicators [3]-[5]: Five representative IARD surveys on Italian young people, extracting data for people aged 15-24. As religious participation declines with age, and as age distribution within age class 15-24 changed between 1983 and 2000 , the data of Rostan (2002) were corrected, standardising by age and considering specific rates by age in 1983 as reference. The meaning of each indicator published here for each year is as follows: what the proportion of people (e.g., attending church at least 2-3 times a month) that would have been if age distribution within age class 15-24 had been the same as in 1983. According to our ageadjusted indicators, decline in religiosity is smoothed, because of the "aging" of young people (within class 15-24, the proportion aged 21-24 changed from $37 \%$ in 1983 to $49 \%$ in 2000). For example, unadjusted values of Rostan's indicator [4] for five years are: $36.4,36.7,34.9,34.8$ and 31.6. 


\section{$2.2 \mathrm{Sex}$}

For Italian cohorts born in the first half of the 20th century, sexual initiation occurred according to a double-standard system, which becomes even more marked when compared with central and northern European countries (Castiglioni and Dalla Zuanna, 1995; Bozon and Kontula, 1998; Bozon, 2003; Castiglioni, 2004). For men, the median age at first intercourse was around 18-19, and the "first time" was generally experienced outside a couple relationship, often with older women or prostitutes - Italy was one of the last European countries to ban brothels in 1958. Most of women had their first intercourse at marriage or with their husband-to-be just before marriage, at an average age of 21-22. Of all women born in the 1940s, more than half were virgins at marriage.

In Italy, things started to change with the cohorts born in the 1950s. For men, the age at intercourse is almost unchanged. What has changed is the context of sexual initiation, which generally takes place either within a steady couple relationship or in an occasional encounter with girls of the same age. For women, the age at intercourse is now equal to that of men in the centre and north, while in the south women on average have intercourse one year older than men.

For the first cohorts (born in the 1950s), the sexual revolution took place at the same time as the decrease in average age at marriage, which in Italy reached the minimum level of 22.5 for women born in 1951-1955 (De Sandre et al., 2000). For the cohorts born later, the age at marriage increased rapidly to over 27 for women born in the mid-1970s. Unlike Northern and Central Europe, and like other Mediterranean countries, in Italy this sudden increase of age at marriage was not matched by more frequent cohabitation or house-sharing with friends or living on one's own. ${ }^{6}$ On the contrary, many unmarried Italians continue to live with their parents beyond their 30s. As a consequence, Italians born in the first half of the 1970s have experienced a long sexually active period (10-12 years for men, 8-10 years for women) while living with their parents and with the need to avoid pregnancies. It is thus not surprising that their contraceptive practices are very high (75\% of them used some contraceptive method at first intercourse, against 33\% of the cohort born twenty years earlier - De Sandre et al., 2000), and their frequency of sexual intercourse has been restrained (Castiglioni et al., 2001).

In conclusion, the sexual revolution did take place in Italy too, but with particular features which differ from those of other countries, although similar, for example, to Spain, as the outcome of national research show (INE, 2004). The sexual behaviour of young Italians born in the 1970s may be summed up in three adjectives: belated,

\footnotetext{
${ }^{6}$ Cohabitation among young people is now spreading in Italy as well, and this trend may continue in future years (Rosina, 2004). But, even those who choose cohabitation leave the parental home at an older age when compared with the countries of Central and Northern Europe: in Italy, we speak of cohabitation of young adults rather than young people.
} 
moderate, and cautious. Belated, because 18-19 years old is a higher age for first intercourse than that observed in other European countries, not mention the USA and other overseas Anglo-Saxon countries. Moderate, because of the low frequency of intercourse, caused by the fact that the partners do not live together. Cautious, because of strong contraceptive cover. One positive outcome of this behaviour is that there are few young single mothers in Italy, and teenage pregnancy rates are among the lowest in developed countries.

\subsection{Religion and sexual behaviour and attitudes}

In Italy, as elsewhere, religiosity and sexuality are closely linked. This association already quite strong in the years preceding the sexual revolution (Fabris and Davis, $1978)^{7}$ - emerges for the younger cohorts as well.

The greater number of statistically valid analyses on Italian national samples refer to connections between church attendance on Sundays and age at first intercourse (Ongaro, 2001; Cazzola, 1999; Castiglioni, 2004). Some of the results of a study on this topic are listed in table 2. For young Italians born in 1966-1977 and interviewed in 1996, attending mass on Sundays was the variable particularly associated with the statistical risk of engaging in first sexual intercourse. Among girls, the median age at first intercourse ranged from 18.6 among those never going to mass, to 21.4 among those going to mass at least once a week. Among boys of the same two groups, the median age ranged from 17.9 to 21.2. Generally, the authors of the above studies explain these results as a sign of the effect of religiosity on sexual behaviour. However, until now in Italy it has never been possible to study the direction of this relation thoroughly. In the surveys on sexual behaviour, church attendance was asked at the time of interview. Quoting Castiglioni (2004, p. 29): "Religious youth delay their entry into sexual life, behaving consistently with the Church's teaching. However, an inverse mechanism could be also operating. A precocious sexual activity could increase the distance from the Church's moral norms, which could later lead them away from religious practice".

The association between sexuality and religion among young Italians has also been studied from other sexual aspects and, more generally, from that of SMR behaviour and attitudes. The results are very similar to those described in the Introduction: in some aspects, Catholics are strongly characterised, whereas in others the differences are much smaller. The differences between Catholics and young people without religion are also

\footnotetext{
${ }^{7}$ As far as we know, the survey by Fabris and Davis - carried out in early 1977 - is the only extensive study on a representative sample of the Italian population. The authors present several tables in which religiosity is crossed with diverse aspects of sexuality. Although lacking more complex statistical models (it was not possible to control for spurious relations), the association of the two variables was almost always strong for both young people and adults, for sexual behaviour both inside and outside marital life.
} 
closely related to some SMR attitudes. All the hypothetical behaviour listed in table 3 is condemned by the Catholic ethic. Nevertheless, the proportion of Catholics who do not accept these attitudes changes considerably (from $31 \%$ for cohabitation to $68 \%$ for abortion), and the same happens for differences between Catholics and people far from any religion, although the differences between the two groups are always statistically significant.

Table 2: $\quad$ Effects of church attendance on risk of first sexual intercourse. Odds ratios estimated from four Cox regression models for a representative sample of Italian men and women born in 1966-77 living the centre-north and southern regions, interviewed in $1996{ }^{1}$

\begin{tabular}{lllll}
\hline Attendance of religious services & \multicolumn{2}{c}{ Men } & \multicolumn{2}{c}{ Women } \\
& centre north & south & centre north & south \\
\hline Never & $2.5^{* *}$ & $1.9^{* *}$ & $1.9^{* *}$ & $2.3^{*}$ \\
$1-2$ times every three months & $2.1^{* *}$ & $1.5^{+}$ & $1.8^{* *}$ & $1.5^{++}$ \\
$1-2$ times a month & $1.8^{*}$ & $1.4^{+}$ & $1.7^{* *}$ & $1.6^{*}$ \\
Once a week or more (reference) & 1 & 1 & 1 & 1 \\
Total (censored) & $342(60)$ & $250(49)$ & $350(54)$ & $265(76)$ \\
\hline
\end{tabular}

${ }^{* *}<0.01{ }^{*} 0.01<\mathrm{p}<0.05^{++} 0.05<\mathrm{p}<0.10{ }^{+} 0.10<\mathrm{p}<0.20$

${ }^{1}$ The following variables are pooled in each of the four models: Population in place of residence $(<$ or $>10,000)$; Education (low, medium, high); Going out at night (never, 2-3 times a week, every night); Going to discos (once a month or more, 1-2 times every three months, never in the past three months); To be successful it is better... (to risk, to be prudent); Frequency of risk in everyday life (often, frequently, sometimes, never); Ever taken drugs (yes, no); Satisfaction with physical appearance (very, quite, not satisfied); Satisfaction with psychological tranquillity (very, quite, not satisfied). Other variables do not appear in the models as they are not statistically relevant: parents' social class and education; relationships and affective communications within the family; number of siblings; out-of-school activities.

Source: Castiglioni, 2004. 
Table 3: $\quad$ Contrasting some ethical attitudes between young Catholics and people without religion ${ }^{1}$. Italian young people aged $15-34$ interviewed in 2000. Percentage that agree ${ }^{2}$.

\begin{tabular}{llll}
\hline & $\begin{array}{c}\text { Catholics } \\
(1)\end{array}$ & $\begin{array}{l}\text { Far from any religion } \\
(2)\end{array}$ & $\begin{array}{c}\text { Ratio } \\
(2) /(1)\end{array}$ \\
\hline It is admissible... & & & \\
$\ldots$.. to cohabit without marriage & 79 & 96 & 1.22 \\
$\ldots$ to have extramarital sexual intercourse & 77 & 94 & 1.22 \\
$\ldots$ to try to have a child using IVF & 67 & 84 & 1.25 \\
$\ldots$ to get a divorce & 63 & 89 & 1.41 \\
$\ldots$ to have homosexual experiences & 38 & 69 & 1.82 \\
$\ldots$ to have sex with a married person & 33 & 63 & 1.91 \\
$\ldots$ to have an abortion & 32 & 74 & 2.31 \\
Total & $(405)$ & $(202)$ & --- \\
\% on total sample & $27.2 \%$ & $13.5 \%$ & --- \\
\hline
\end{tabular}

\section{Hypotheses and methodology}

Our main aim was to study the reciprocal influence between sexuality and religion among young Italians. In particular, we focus on the sexual debut and on discontinuing church attendance. These events are the outcome of processes which interact dynamically. "Without correctly specifying the causal influence in both directions, empirical estimates of the impact of religion on adolescent sexuality will be biased" (Thornton and Camburn, 1989). Nevertheless, often the two processes are in fact separately analysed, or cross-sectional data are used that do not allow separation of the reciprocal effect (Rostosky et al., 2004). "There are very few studies that have explored possible reciprocal relationships between religiosity and first sex" (Meier, 2003). As a consequence, "our empirical understanding of the association between religiosity and adolescent sexual behaviour is fairly limited" (Hardy and Raffaelli, 2003).

From a methodological point of view, we analyse retrospective longitudinal data with event history models which explicitly consider the endogeneity of one event as a 
predictor of the other, by taking into account both heterogeneity across individuals due to unobserved factors that may affect each of the two processes, and correlations in unobserved factors across processes (Lillard and Waite, 1993; Lillard et al. 1995). The timing of events (first sexual intercourse and discontinuing church attendance) is expressed in terms of the life of the individual, starting from 13 years old. We also explicitly take into account selection, as we confine analysis to the sub-sample of those who, at the beginning of the process (aged 13) attended church and were virgins. Since basically all individuals analysed (with some rare exception) were virgins at 13 , the selection mechanism is relevant only for religious participation.

From an operational point of view, the hypotheses we wished to verify are the following. Several studies have highlighted the important role played by religiosity on sexual behaviour. The results in the literature essentially agree that church attendance reduces the likelihood of coital debut and is also positively associated with greater perception of the risk of contracting HIV or becoming pregnant due to unprotected intercourse (Miller and Gur, 2002). The Catholic Church reinforces values which discourage young people from engaging in precocious or in any case premarital sexual intercourse. Respecting these values is particularly strong among young people who often attend religious events: they "receive frequent religious messages concerning premarital sex, and their religious involvement may facilitate their acceptance of the teaching of their religious institutions". Thus, they are "more likely than others to develop sexual attitudes and behaviour that are consistent with religious teachings" (Thornton and Camburn, 1989). Our first hypothesis is therefore the following:

H1: "Religiosity effect": net of common factors (observed and unobserved), discontinuing church attendance has a positive effect on the risk of one's first sexual experience.

Many scholars suggest that, together with the effect of religion on sexual behaviour, there may also be a reciprocal influence between sexual behaviour and religiosity (Thornton and Camburn, 1989; Benda and Corwyn, 1997; Rostosky et al., 2004). However, results in this direction are controversial and, in particular, are not statistically significant for young Americans (Meier, 2003; Hardy and Raffaelli, 2003). However, from a theoretical point of view, for young religious people the fact of having experienced premarital sex is likely to produce a cognitive dissonance (Festinger, 1957) with the religious values that oppose such behaviour. The solution to this inconsistency between behaviour and values may be of two kinds. First, young people, especially if the sexual experience was positive and satisfying, may distance themselves from religion (religiosity adaptation): " the discrepancy between the individual's own values

8 "[...], meaning that the behaviour causes the individual to change his or her religious values" (Meier, 2003). 
and the official position of the church will alter the individual's relationship with the religious institution. The authority of the Church may be questioned, the commitment to the institution weakened, and the involvement in church services restricted" (Thornton and Camburn, 1989). Conversely, in a context characterised by more moralistic and conservative beliefs about sex, the coital debut, especially if emotionally unsatisfying, may be followed by a sense of guilt which temporally blocks the sexual experience and reinforces religious involvement: "a sexuality experienced religious teen can reduce cognitive dissonance [...] by ceasing to engage in sexual activity" (Hardy and Raffaelli 2003). In the literature, the effect that is considered to be prevalent is the first one (adaption effect). We therefore propose the following hypothesis.

H2: "Adaptation effect": net of common factors (observed and unobserved) the sexual debut has a positive effect on discontinuing church attendance.

The strength of the relationship between sex and religion may be genderdifferentiated (Meier, 2003; Rostosky et al., 2003). Even control factors may have a differentiated impact on gender (for Italy, see, for example, Castiglioni, 2004). This suggests that separate analyses should be carried out for males and females.

The control variables explicitly included in the model capture the influence of the geographical context in which the young people live and of the cultural and religious orientation of their parents. Parental values are important determinants of young adults' behaviour (Thornton and Camburn, 1987, 1989; Miller and Moore, 1990) and this is also true in Italy (Rosina and Fraboni, 2004). Studies on sexual behaviour have also shown that the southern regions of Italy are more traditionally oriented than those of the north (Rosina and Rivellini, 2004). Lastly, since the relation between first sexual experience and religion may be substantially affected by the fact of living in a couple relationship, we also consider the involvement in a couple relationship as a control variable.

The existence of unobserved factors that may influence both processes must also be taken into account. Some of these may influence both domains simultaneously and generate a potentially spurious correlation. To estimate bi-directional causal effects correctly, it is therefore important to allow for correlations among the unobserved heterogeneity terms of each process (Lillard, 1993; Coppola, 2004). This heterogeneity represents the unobserved factors which affect individual choices, mainly attitudes and values. From a theoretical point of view, the correlation between unobserved heterogeneity of the two processes may be either positive or negative. It is positive when the unobserved heterogeneity contains prevailing factors that concomitantly act by increasing (or diminishing) the risk of both first sexual intercourse and church discontinuance. An example of a factor of this kind is the degree of autonomy and 
freedom, personal values being equal, transmitted by parents to their adolescent children choices. The degree of cultural opening-up towards the children's choices, even though they are not strictly approved of by parents, is only partly explicitly kept under control through parents' educational level. There may also be a negative correlation, when the unobserved heterogeneity contains prevailing factors which favour a conciliation between sexual experience and religious participation. For example, the Catholic religion may be experienced without giving much importance to its prescriptive aspects, and laying more emphasis on the positive message of love, trust and openness towards others. Having an affective couple relationship with a partner who shares this same idea of religion may favour a positive interaction between religion and sexuality within a couple.

As all these factors may merge in the unobserved heterogeneity, we cannot state the sign of correlation among the common latent factors of the two processes a priori

\section{Data and variables}

\subsection{Data}

Our data were collected in a survey on the sentimental and sexual life of Italian university students (Sex of Italian Students - SIS). A national representative sample of about 5,000 students attending first- and second-year courses in the Faculties of Economics and Statistics from December 2000 to June 2002 was interviewed.

The Italian Faculties of Economics and Statistics were stratified, ${ }^{9}$ in order to represent the different socio-economic situations of students (Dalla Zuanna and Crisafulli, 2004a). For each stratum, one or more universities were sampled, and all first- and second-year students being in the classroom on a "normal" day were interviewed. Thus, about 5,000 students from 23 universities were interviewed; the sampling method was a two-step cluster sampling technique, with preliminary stratification of units at the first step. The random process works only in the first step (i.e., choice of universities), as all the second-step units (i.e., students in the classroom on the day of the survey) were interviewed. This technique is frequently used for collecting data in the schools, because it is very cheap.

The Faculties of Economics and Statistics were chosen because they both have a very high percentage of students attending lessons regularly. In addition, the numbers of males and females are more balanced in these faculties, and it was easy for the research

\footnotetext{
${ }^{9}$ Students in different faculties probably have different background characteristics, and consequently engage in different patterns of behaviour.
} Therefore, stratification would have been very difficult, unless sampling designs which are expensive, complex and hard to manage were used. 
team to have successful contacts with academic authorities. Students attending courses in the few private Italian universities were not included in the sample, because they are selected on the basis of family income, skills, and religion.

The questionnaire was composed of about 200 closed questions covering 16 pages and took around 30 minutes to complete. It collected information on respondents' personal and parental background, quality of the relationship with parents, religiosity (including church attendance of both students and their parents), at-risk behaviour, friendship network, first sexual intercourse, romantic relationships, and living arrangements. A final section dealt with opinions and attitudes concerning various aspects of affective and sexual behaviour. Most information refers to different stages of adolescence (ages 11-13, 14-15, 16-18).

The questionnaires were filled in during a one-hour lesson, under the discreet surveillance of both the professor of the course and a researcher, who presented the survey and was ready to answer questions, if any. The researcher informed the students that the questionnaires were anonymous and would not be used at an individual level. After they had been filled in, the questionnaires were sealed in an envelope and recollected. This practically resulted in no refusals to fill in the questionnaires in class. It is a significant improvement compared with at least 20-30\% of refusals in face-toface or CATI interviews, both in Italy and elsewhere (see, e.g., Bajos and Spira, 1993).

The main problem of self-filled questionnaires is the high non-response rate. For each question of the SIS survey, non-responses were always lower than $10 \%$. The month at first intercourse (15\% of missing data in the sample) and at first steady relationship ( $24 \%$ of missing data) were exceptions, probably because they are more difficult to recall. They were replaced according to the distribution of known values.

The size of our sample (about 5,200) was a significant improvement when compared with previous studies on sexual life carried out in Italy, which were usually made on smaller samples. The respondents were males (42\%) and females (58\%), mainly unmarried, born between 1975 and 1982, and aged between 18 and 26 years at interview (median age about 20.5; and 77\% 19-21 years old).

Questionnaires in which the year of birth or gender of the respondent were not stated, or ones that had too many missing or invalid answers, were excluded. Since we had decided to restrict our study only to young people who were adolescents in the last decade of the 20th century, all respondents who were born before 1975 were also excluded. Thus, the questionnaires available for analysis numbered 4,998. We further excluded questionnaires from which it was impossible to determine first intercourse (63 people) or the year (125), when students stopped attending church (85), or if they had ever gone to church (310), stated that they had first intercourse before the age of 13 (31) or had pooled some of these characteristics (326). Thus, our sample was finally reduced to 4,058 . 
The 950 people excluded from analysis because of these non-responses were sexually more precocious. The median age at first intercourse of the 4,058 people finally analysed was 19.5 for both males and females, whereas it was 18.9 for males and 19.2 for females when all the 4,498 people who answered the question on age at first intercourse were taken into account, without excluding those who did not correctly fill in the answers on frequency of church attendance. Consequently, the "sexual delay" of the group analysed here is even more accentuated, mainly for males. Moreover, as they answered questions on frequency of church attendance, they may be more interested in religious issues.

Apart from these selection problems, the final group has some important advantages: a high number of interviewees, an above-average cultural level (an appreciable characteristic for a self-filling, although not complex, questionnaire), and a very low number of refusals. However, university students of Economics and Statistics (faculties not considered as the easiest in terms of commitment, in Italy as elsewhere) are a particular group: they invest many personal and family resources in education, are subject to greater expectations from their families, and thus usually delay the formation of their own families.

There is a long tradition of studies on the sexual life of students (see, e.g., Reinisch et al., 1992; Sprecher and Regan, 1996; Murray et al., 1998; Denissenko et al., 1999; Whitbeck et al., 1999). Generally, students delay sex more than early workers (see Miller and Moore, 1990, and Kontula, 2004, for reviews), particularly if - during their lives as students - they live with their parents (see Castiglioni, 2004, and Rosina and Rivellini, 2004, for some results on Italy). Nevertheless, the sexual behaviour and church attendance of our sample are not particularly far removed from the general Italian rules. The median age at first intercourse is around 19.5, and students attending church at least 2-3 times a month at their 19th birthday (around the beginning of the first year at university in Italy) are $25 \%$ for males and $40 \%$ for females (table 4). Moreover, their church attendance has rapidly declined during their teens, as the proportions going to church at least 2-3 times a month when they were 13 were $70 \%$ for males and $83 \%$ for females.

Therefore, although these students are not representative of Italian young people as a whole, the direction of selection is well-known, and the timings of their sexual initiation and discontinuing church attendance are not far from those of the average ordinary Italians. 
Table 4: Proportion of SIS students who stopped going to church and experienced their first sexual intercourse, by sex and exact age. Kaplan-Meier calculations (SPSS 11.0 software).

\begin{tabular}{|c|c|c|c|c|c|c|c|c|}
\hline & \multicolumn{8}{|c|}{ Exact birthdays } \\
\hline & 13 & 14 & 15 & 16 & 17 & 18 & 19 & 20 \\
\hline & \multicolumn{8}{|c|}{ Males $(n=1,615)$} \\
\hline$\%$ attending church & 70.1 & 63.9 & 53.4 & 44.8 & 37.4 & 30.3 & 24.9 & 22.6 \\
\hline \multirow[t]{2}{*}{$\%$ virgins } & 100 & 99.6 & 96.7 & 91.2 & 83.4 & 69.7 & 55.9 & 46.2 \\
\hline & \multicolumn{8}{|c|}{ Females $(n=2,443)$} \\
\hline$\%$ attending church & 82.8 & 77.4 & 68.4 & 59.2 & 51.0 & 45.5 & 39.8 & 35.9 \\
\hline$\%$ virgins & 100 & 99.9 & 97.2 & 92.6 & 82.3 & 70.0 & 55.8 & 47.8 \\
\hline
\end{tabular}

Source: Micro-data of Survey on Italian Students. 4,058 people who correctly answered questions on age at first intercourse and age at stopping church attendance.

\subsection{Variables}

A list of the variables used in our analysis is given below (see distribution in table 5).

Experienced first steady relationship (time-varying). Students were asked: Have you ever had a steady relationship? If so, when did it begin? Possible answers were: month and year, or never happened.

Experienced first sexual encounter (time-varying). Students were asked: Have you ever had sexual intercourse? If so, when did it happen for the first time? Possible answers were: month and year, or never happened.

Church attendance at 13 years old. Students were asked: Apart from such special occasions as weddings, funerals and baptisms, how often did you attend services connected with your religion when you were 13 years old? The answers were grouped into two subgroups: irregular church attendance (at least about once a month), and regular attendance (at least 2-3 times a month). In our opinion, this question was easy for students to answer, as in Italy the 13th year of age is a "year of passage", dividing pre-adolescence from adolescence. Most people receive the sacrament of Confirmation - after some months of specific religious education - during the 13th year of age, which is also the last year of junior high school in Italy. 
Age at stopping church attendance. Students were asked: How old were you when you stopped going regularly to church? There were three possible answers: age (in years), I never went to church regularly, or I still go to church regularly. Although discontinuing church attendance may be a process rather than a single event, the essence of our work was that the age declared by students was not far from the "average age" of their effective discontinuance of the religious habits of his/her pre-adolescence period. As table 4 shows, for many students this age is not far from the time of the interview, and this narrow time-spam suggests that remembering the timing of the event is easier.

Church attendance (time-varying). We created this time-varying variable by putting together the information from three variables: a) church attendance at 13 years old, b) church attendance at the interview (the possible answers were the same as for age 13), c) age at stopping church attendance. We created three subgroups: never went to church (never or sometimes during the year), went to church irregularly (at least once a month), went to church regularly (2-3 times a month to once a week or more).

Father's and mother's church attendance when students were 13 years old. Students were asked: Apart from such special occasions as weddings, funerals and baptisms, how often did your father and mother attend services connected with their religion when you were 13 years old? Again, we divided the answers into three subgroups: never went to church (never or sometimes during the year), went to church irregularly (at least once a month), went to church regularly (2-3 times a month to once a week or more).

Parents' education. Students were asked: What was the highest level of schooling your mother and father finished? Four subgroups were created: a) lower education (high school not completed, or lower) of both mother and father; b) lower education of father and higher education (completed high school or higher) of mother; c) higher education of father and lower education of mother; d) higher education for both parents.

Geographical area of residence. Italian provinces were grouped into two macroareas: north centre, and south. The importance of this control variable for Italian young people's behaviour is well-known (e.g., Billari and Borgoni, 2002). 
Table 5: Percentual distribution of variables used in statistical models (see table 8)

\begin{tabular}{|c|c|c|c|c|}
\hline \multirow[b]{2}{*}{ VARIABLE } & \multicolumn{2}{|c|}{ All respondents } & \multicolumn{2}{|c|}{$\begin{array}{r}\text { Those who } \\
\text { attended church at } 13\end{array}$} \\
\hline & male & female & male & female \\
\hline \multicolumn{5}{|c|}{ Church attendance at 13} \\
\hline Always & - & - & 89.9 & 93.5 \\
\hline Sometimes & - & - & 10.1 & 6.5 \\
\hline \multicolumn{5}{|c|}{$\begin{array}{l}\text { Father's church attendance } \\
\text { when respondent was } 13\end{array}$} \\
\hline Weekly & 32.0 & 31.8 & 43.9 & 38.2 \\
\hline Sometimes & 6.3 & 5.7 & 7.4 & 6.0 \\
\hline Never & 61.7 & 62.5 & 48.7 & 55.8 \\
\hline \multicolumn{5}{|c|}{$\begin{array}{l}\text { Mother's church attendance } \\
\text { when respondent was } 13\end{array}$} \\
\hline Weekly & 49.6 & 49.6 & 63.4 & 59.0 \\
\hline Sometimes & 7.2 & 8.0 & 7.6 & 7.6 \\
\hline Never & 43.2 & 42.4 & 29.0 & 33.4 \\
\hline \multicolumn{5}{|c|}{ Geographical area of Italy } \\
\hline Centre-north & 69.2 & 61.7 & 69.8 & 60.4 \\
\hline South & 30.2 & 36.8 & 29.6 & 38.8 \\
\hline Outside Italy & 0.6 & 1.5 & 0.6 & 0.8 \\
\hline \multicolumn{5}{|c|}{ Education of parents } \\
\hline F low, M low & 23.8 & 33.2 & 23.7 & 34.4 \\
\hline F high, M low & 13.9 & 14.4 & 15.2 & 14.8 \\
\hline F low, M high & 10.7 & 11.4 & 10.1 & 11.6 \\
\hline $\mathrm{F}$ high, $\mathrm{M}$ high & 51.6 & 41.0 & 51.0 & 39.2 \\
\hline Number & 1,615 & 2,443 & 1,046 & 1,911 \\
\hline
\end{tabular}

\section{Results}

We studied the interdependence between the first sexual encounter and religiosity, considering two groups of people separately (Italian male and female students). Specifically, we studied the net effect of DCA (discontinuing church attendance) on FSI (first sexual intercourse) and, conversely, the net effect of FSI on DCA. We selected as 
the target population young people who at 13 attended church at least once a month (about $72 \%$ of the total sample).

In a first stage, we analysed separately the two processes (FSI and DCA), without taking into account unobserved heterogeneity or the correlation between the parallel processes. They are two separate event history analyses, in which one process is used as an explanatory time-varying variable of the other.

The Appendix illustrates some further stages in which we estimated models that are statistically more sophisticated and complex. In these models, as already stated in detail in section 3, we controlled for unobserved factors, allowing the random effects of the two regression equations to be correlated. A selection equation is also included, in order to control for selectivity in both processes (some people did not go to church at least once a month when they were 13 years old). Apart from model refinement, the statistical relations between DCA and FSI processes work in the same direction. Consequently, in the following section we prefer to comment on the regression coefficients connecting FSI and DCA of the simple event history models, since they are less affected by random variations of the estimates of coefficients (Aasave et al., 2003). The complete results are shown in the Appendix.

For both sexes, we find a positive and significant effect of the time-varying covariate DCA on the FSI process, and vice versa (table 6). These results are consistent with the H1 ("religiosity effect") and H2 ("adaptation effect") hypotheses (see part 3). The effects are more intense for females, except for FSI $\rightarrow$ DCA, which is slightly higher for males. As stated above, these results do not change when models are more "complicated", controlling for unobserved heterogeneity, considering the correlation between the two processes and possible selection mechanisms (see table 8, Appendix).

\section{Table 6: Effects (relative risks) of ceasing to go to church after first sexual intercourse and first sexual intercourse after ceasing to go to church.}

\begin{tabular}{lcc}
\hline & $\underline{\text { Males }}$ & $\underline{\text { Females }}$ \\
$\begin{array}{l}\text { Discontinued Church Attendance } \rightarrow \\
\text { First Sexual Intercourse }\end{array}$ & 1.76 & 1.81 \\
$\begin{array}{l}\text { First Sexual Intercourse } \rightarrow \\
\text { Discontinued Church Attendance }\end{array}$ & 1.64 & 1.79 \\
\hline
\end{tabular}

Notes: see complete models in Appendix, table 8, model (1).

All coefficients are statistically significant $(p<0.01)$ 


\section{Conclusions and discussion}

About 55\% of Italian 20-year-old university students in our sample stated that they had had sexual intercourse. The chances of experiencing this event were conditioned by their religious behaviour: those who attend church remain virgins for longer. This result is very similar to findings in many other studies on the topic. Yet, for Italy, until now it has never been possible to identify the direction of the causal effect. Moreover, the effect persists when we accounted for unobserved common factors, providing empirical evidence of the hypothesis of a "genuine" (not spurious) effect of DCA on sexual debut.

$32 \%$ of students in our sample went to church at least twice a month. This proportion, although high in comparison with other industrialised countries, is lower than what it was at 13 - as retrospectively stated by the interviewees. The process of religious estrangement is interrelated with the onset of affective and sexual life. For both boys and girls, the first couple experience and - especially - first sexual intercourse, accelerate detachment from religious practice. This result, common to all our models, and stronger when we examine any possible correlation between the processes due to unobserved common factors, is not in line with results from the USA (see, e.g., Meier, 2003): young Americans do not significantly change their religious habits after their first sexual intercourse. ${ }^{10}$

In our opinion, this difference between Italy and the USA is one of the most interesting results of this study. To explain what it actually means, it is useful to refer back to the first part of this paper. Sexual, marital and reproductive behaviour not in line with the ethical norms of a religion may affect feeling of closeness to that religion if the incompatibility is felt at both individual and collective levels, and if there are institutions reinforcing rules and obliging followers to comply with them.

In today's Italy, it is hard to believe that a priest can deny Holy Communion or access to an event organised by the Church to young people who are "suspected" of having engaged in premarital sex. However, in Italy, the Church is extremely good at involving adolescents. In addition, more than in other countries, the Italian mass media echoes the precepts of the Catholic hierarchy, especially those of the Pope, and traditional norms are vigorously reinforced, leaving little room for individual interpretation. What is more, in Italy - unlike the USA, where many Christians belong to churches with less rigorous views against pre-marital sex - the Catholic Church is ubiquitous, and "conflict" with other religions and churches is practically non-existent. Therefore, for young Catholics, it is difficult to be exposed to religious opinions which are not those proposed by the Catholic Church and they are more unlikely to be

\footnotetext{
${ }^{10}$ It is not easy to say if the result discussed here is applicable to the whole population, or if it is specific only to our students. On one hand, students may have a more "rational" approach, less inclined to accept a conflict between doctrine and behaviour. On the other hand, students may be culturally better equipped to create their own "individual religion", at the same time - in their conscience - fully accepting the precepts of the Church and engaging in premarital sexual intercourse.
} 
involved in an affair with a person belonging to another religion. In this context of religious monoculture, many young people probably clearly perceive the incompatibility between sexual intercourse and Catholic affiliation. As a consequence, for many of them first sexual intercourse may accelerate voluntary detachment from the Catholic Church.

Lastly, we would like to define the "boundaries" of our results better. We have shown a reciprocal effect between the two processes of the onset of adult sexuality and estrangement from regular religious practice. However, in Italy, the large majority of practising young Catholics - even with delayed first sexual intercourse - do not reach marriage as virgins. As shown in table 3 for Italy, only 33\% of young Italian Catholics going to church at least once a month, interviewed in 2000 , stated that sexual intercourse before marriage was inadmissible. This idea of reciprocal compatibility between sex and religion is also confirmed by the behaviour of our students (table 7): many of them regularly go to church although they have already experienced sexual intercourse, and many who have experienced it regularly go to church. Among the churchgoer, non-virgin people are $36 \%$ (m) and 39\% (f), and among non-virgin the churchgoers are $23 \%$ (m) and $30 \%$ (f). It is difficult that all the non-virgin churchgoers go to church because of social pressure: most of them do not live in remote villages, and many live far from their families. ${ }^{11}$

Table 7: All university students aged 19-21 by sexual intercourse and church attendance

\begin{tabular}{llrr}
\hline & Males & Females \\
\hline 1 & Virgins going to church at least once a month & 15.2 & 20.4 \\
2 & Non-virgins going to church at least once a month & 8.5 & 13.3 \\
3 & Virgins not going to church at least once a month & 23.2 & 19.9 \\
4 & Non-virgins not going to church at least once a month & 53.1 & 46.4 \\
& Total & 100.0 & 100.0 \\
\hline
\end{tabular}

Consequently, bricolage religion (or better, the bricolage sexual ethic) is an important component of the approach to sexuality, also for Catholic students in Italy. This extensive reciprocal coexistence between affiliation to the Catholic religion and sexual experiences condemned by the Catholic religious ethic is also a signal of the relative flexibility of Catholicism, confirming the results of other recent comparative studies (McNamara Barry and Nelson, 2005).

11 In this paper, social pressure was only measured by means of individual-level indicators. In future research, it may be interesting to adopt other approaches, e.g., examining whether the reciprocal association between FSI and DCA is stricter in the more "traditional" areas. This hypothesis may be verified by a multilevel approach (e.g., clustering students by province, putting both individual-level and province-level indicators) in the regression models, and/or reprocessing data separately in areas characterised by different levels of church attendance and different ages at sexual debut. 


\section{References}

Aasave A., Billari F. C., Michielin F., Panis C. (2003) A Monte Carlo study of (simultaneous) hazard models with flexible baseline and normally distributed error terms. Paper presented at PAA 2003 Annual Meeting, Minneapolis (USA), 1-3 May 2003.

Barbagli M., Castiglioni M., Dalla Zuanna G. (2004) Fare famiglia in Italia, Il Mulino, Bologna.

Baizán P., A. Aassve and F.C. Billari (2003) Cohabitation, marriage, and first birth: the interrelationship of family formation events in Spain, European Journal of Population, 19, 147-169.

Bajos, N. and Spira, A. (1993) The ACSF survey: setting up a multidisciplinary study of sexuality, Population, 48, 1,209-1,227.

Benda, B. B., and Corwyn, R. F. (1997) A test of a model with reciprocal effects between religiosity and various forms of delinquency using 2-stage least-squares regression, Journal of Social Services Research, 22, 27-52.

Berndt E.R., B.H. Hall, R.E. Hall, J.A. Hausman (1974) Estimation and inference in nonlinear structural models, Annals of Economic and Social Measurement, 3, 653-665.

Billari F.C. and R. Borgoni (2002) Spatial profile in the analysis of event histories: an application to first sexual intercourse in Italy, International Journal of Population Geography, 8, 261-275.

Bozon M. (2003) At what age do women and men have their first sexual intercourse? World comparisons and recent trends. Population and Societies, 391, 1-4.

Bozon M. and O. Kontula (1998) Sexual initiation and gender in Europe. A crosscultural analysis of trends in the twentieth century, in M. Hubert, N. Bajos and T. Sandfort (eds.) Sexual behaviour and HIV/AIDS in Europe. Comparison of national survey, UCL Press, London, UK.

Brewster K.L, E.C. Cooksey, D.K. Guilkay and R.R. Rindfuss (1998) The changing impact of religion on the sexual and contraceptive behaviour of adolescent women in the United States, Journal of Marriage and the Family, 60, 493-504.

Caritas Italiana (2003) XIII rapporto sull'immigrazione in Italia, Rome.

Castiglioni M. (2004) First sexual intercourse and contraceptive use in Italy, in G. Dalla Zuanna and C. Crisafulli (eds.), 19-39. 
Castiglioni M. and G. Dalla Zuanna (1995) Some indications on trends of reproductive behaviour of never married women in Italy, in IRP-CNR: Contribution of Italian Scholar at the European Population Conference (EAPS), 5-21.

Castiglioni M., G. Dalla Zuanna and M. Loghi (2001) Planned and unplanned births and conceptions in Italy 1970-1995, European Journal of Population, 17, 3, 207-233.

Cazzola A. (1999) L'ingresso nella sessualità adulta, in P. De Sandre, A. Pinnelli and A. Santini (eds.), Nuzialità e fecondità in trasformazione: percorsi e fattori del cambiamento, Il Mulino, Bologna, Italy, 311-325.

Cesareo V., R. Cipriani, F. Garelli, C. Lanzetti and G. Rovati (1995) La religiosità in Italia, Mondadori, Milan, Italy.

Coppola L. (2004) Education and union formation as simultaneous in Italy and Spain, European Journal of Population, 20, 219-250.

Dalla Zuanna G. and C. Crisafulli (2004a) The survey on Italian students: theoretical background and the framework of data collection, in: Dalla Zuanna G. and C. Crisafulli (eds.), 77-86.

Dalla Zuanna G. and C. Crisafulli (eds.) (2004b) Sexual behaviour of Italian students, Dipartimento Statistico, Università di Messina. Downloading in PDF format: http://homes.stat.unipd.it/gpdz/

Denissenko M., Dalla Zuanna G., Guerra D. (1999) Sexual behaviour and attitudes of students in the Moscow State University, European Journal of Population, 15, 279-304.

De Sandre P., F. Ongaro, R. Rettaroli and S. Salvini (2000) Fertility and family surveys in countries of the ECE region. Standard Country Report for Italy, Economic Studies no. 100, UN-ECE, New York and Geneva.

Fabris G.P. and R. Davis (1978) Il mito del sesso, Mondadori, Milan, Italy.

Festinger L. (1957) A theory of cognitive dissonance, Harper, New York, USA.

Garelli F., G. Guizzardi and E. Pace (eds.) (2003) Un singolare pluralismo, Il Mulino, Bologna, Italy.

Gervais D. and D. Gauvreau (2003) Women, priests, and physicians: family limitation in Quebec, 1940-1970, Journal of Interdisciplinary History, XXXIV, 2, 293314. 
Goldscheider C. (1971) Population, modernization, and social structure, Little Brown \& Company, Boston, USA.

Hakim C. (2003) A new approach to explaining fertility patterns: preference theories, Population and Development Review, 29, 3, 349-374.

Hardy S. A. and M. Raffaelli (2003) Adolescent religiosity and sexuality: an investigation on reciprocal influences, Journal of Adolescence, 26, 731-739.

Heckman J.J. (1979) Sample selection bias as a specification error, Econometrica, 47, 153-161.

INE (2004) Salud y habitos sexuales, Boletin Informativo del Instituto Nacional de Estadistica, 4, Madrid, Espana.

Kontula O. (2004). Reproductive health behaviour of young Europeans, Volume 2: The role of education and information. Council of Europe Publishing, Strasbourg, France. Downloading in PDF format: http://www.coe.int/population.

Lillard L. A. and C.W.A. Panis (2000) aML user's guide and reference manual. Econware Inc., Los Angeles, USA.

Lillard L.A. (1993) Simultaneous equation for hazard. Marriage duration and fertility timing, Journal of Econometrics, 56, 189-217.

Lillard L.A. and L.J. Waite (1993) A joint model of marital childbearing and marital disruption, Demography, 30, 653-681.

Lillard L.A., M.J. Brien and L.J. Waite (1995) Premarital cohabitation and subsequent marital dissolution: a matter of self-selection?, Demography, 32, 437-457.

Luckmann T. (1979) The structural conditions of religious consciousness in modern societies, Japanese Journal of Religious Studies 6, 121-137.

McNamara Barry C. and L. Nelson (2005) The role of religion in the transition to adulthood for young emerging adults, Journal of Youth and Adolescence, 34, 245-255.

McQuillan K. (2004) When does religion influence fertility?, Population and Development Review, 30, 1, 25-26.

Meier A. M. (2003) Adolescents' transition to first intercourse, religiosity, and attitudes about sex, Social Forces, 81, 1031-1052.

Miller L. and M. Gur (2002) Religiousness and sexual responsibility in adolescent girls, Journal of Adolescent Health, 31, 401-406. 
Miller B.C. and K.A. Moore (1990), Adolescent sexual behaviour, pregnancy and parenting: research through the 1980s, Journal of Marriage and the Family, 52, 1025-1044.

Murray N. J., L. S. Zabin, V. Toledo-Dreves and X. Luengo-Charath (1998) Gender differences in factors influencing first intercourse among urban students in Chile, International Family Planning Perspectives, 24, 139-144.

Ò Grada C. (1991) New evidence on the fertility transition in Ireland 1880-1911, Demography, 28, 535-548.

Okun B. S. (2000) Religiosity and contraceptive method choice: the Jewish population of Israel, European Journal of Population, 16, 109-132.

Ongaro F. (2001), First sexual intercourse in Italy: a shift towards an ever more personal experience?, 24 ${ }^{\text {th }}$ IUSSP General Population Conference, Salvador, Brazil, 18-24 August.

Pisati M. (2000) La domenica andando alla messa. Un'analisi metodologica e sostantiva di alcuni dati sulla partecipazione degli italiani alle funzioni religiose, Polis, 1, 113-138.

Reinisch J. M. Samders S. A. Hill C. A. Ziemba-Davis M. (1992) High risk sexual behaviour among heterosexual undergraduates at a midwestern university, Family Planning Perspectives, 24, 116-121, 145.

Rizzi E. (2004) Religiousness and sexual ethics, in G. Dalla Zuanna and C. Crisafulli (eds.), 249-264.

Rosina A. (2004), Family Formation in Italy: A Cohort Approach, in G. Dalla Zuanna and G.A.Micheli (eds.), Strong family and low fertility: a paradox?, Kluwer Academic Press, Dordrecht.

Rosina A. and R. Fraboni (2004) Is marriage losing its centrality in Italy?, Demographic Research, 11, 149-172.

Rosina A. and G. Rivellini (2004) Living arrangements, trasgressive behaviour and sexuality, in G. Dalla Zuanna and C. Crisafulli (eds.), 125-133.

Rostan M. (2002) Giovani del nuovo secolo, in C. Buzzi, A. Cavalli and A. de Lillo (eds.) Giovani del nuovo secolo, il Mulino, Bologna, Italy, 367-386.

Rostosky S. S., M. D. Regnerus, and M. L. Comer Wright (2003) Coital debut: the role of religiosity and sex attitudes in the Add Health Survey, Journal of Sex Research, 40, 358-367. 
Rostosky S. S., B. L. Wilcox, M. L. Comer, B. A. Randall (2004). The impact of religiosity on adolescent sexual behaviour: a review of evidence, Journal of Adolescent Research, 19, 677-697.

Sprecher, S. and P. C. Regan (1996) College virgins: how men and women perceive their sexual status, Journal of Sex Research, 33, 3-15.

Thornton and Camburn, (1987), The influence of the family on premarital sexual attitudes and behaviour, Demography, 24, 3, 323-340.

Thornton A. and A. Camburn (1989) Religious participation and adolescent sexual behaviour, Journal of Marriage and the Family, 51, 3, 641-643.

Thornton A., W.G. Axinn and D.H. Hill (1992) Reciprocal effects of religiosity, cohabitation and marriage, American Journal of Sociology, 98, 628-651.

Trombetta P.L. (2004) Why does "self-made religion" spread in Italy?, paper presented at CESNUR 2004 international conference: Religious Movements, Conflict, and Democracy: International Perspectives, June 17-20, Baylor University, Waco, TX, USA.

van de Kaa D. (2004) The true commonality: in reflexive modern societies fertility is a derivative, Population Studies, 58, 1, 77-92.

Westoff C.F. and E.F. Jones (1979) The end of "Catholic" fertility, Demography, 16, 209-217.

Whitbeck L. B., K. A. Yoder, D. R. Hoyt and R. D. Conger (1999) Early adolescent sexual activity: a developmental study, Journal of Marriage and the Family, 61, 934-946.

YAA, 1993 The Japanese youth in comparison with the youth in the world, Youth Affairs Administration, Management and Coordination Agency, Tokyo. 


\section{Appendix}

\section{A more complex model...}

We use an event history approach with simultaneous hazard rate equations. To take individual heterogeneity into account, we included the appropriate random effects in each process. To control for unobserved factors which may concomitantly act on both processes, we allowed the random effects of the two regression equations to be correlated (Lillard et al., 1995; Baizán et al., 2003; Coppola, 2004). To control for selectivity in both processes, we included a selection equation in our model.

The statistical specification of the model applied here is derived from the framework developed by Lillard (1993). It consists of two simultaneous hazard rate equations, modelling time (from age 13) to First Sexual Intercourse (FSI) and Discontinuing Church Attendance (DCA), both estimated only on young people who still went to church at 13 at least once a month. We added a selection equation (Heckman, 1979), to take into account the selectivity introduced in the model when only these individuals were included. This was necessary because, as already stated, respondents who were religious at 13 may be a non-random subset of the general population.

The model is the following:

$$
\left\{\begin{array}{l}
\ln h_{i}^{\mathrm{FSI}}(\mathrm{t})=y_{i}^{\mathrm{FSI}}(\mathrm{t})+\sum_{j} a_{j} x_{i j}+\sum_{k} \alpha_{k} w_{i k}(\mathrm{t})+\delta \\
\ln h_{i}^{\mathrm{DCA}}(\mathrm{t})=y_{i}^{\mathrm{DCA}}(\mathrm{t})+\sum_{j} b_{j} x_{i j}+\sum_{k} \beta_{k} w_{i k}(\mathrm{t})+\varepsilon \\
\mathrm{z}^{*}=\sum_{j} c_{j} x_{i j}+\theta, \quad\left\{\begin{array}{l}
\mathrm{z}=0 \text { if } \mathrm{z}^{*} \leq 0 ; \\
\mathrm{z}=1 \text { if } \mathrm{z}^{*}>0 ;
\end{array}\right.
\end{array}\right.
$$

with $\ln h_{i}^{\mathrm{DCA}}(\mathrm{t})$ observed if and only if $\mathrm{z}=1$.

$$
\left(\begin{array}{l}
\delta \\
\varepsilon \\
\theta
\end{array}\right) \sim \mathrm{N}\left(\left(\begin{array}{l}
0 \\
0 \\
0
\end{array}\right),\left(\begin{array}{ccc}
\sigma_{\delta}^{2} & \rho_{\delta \varepsilon} & \rho_{\delta \theta} \\
\rho_{\delta \varepsilon} & \sigma_{\varepsilon}^{2} & \rho_{\varepsilon \theta} \\
\rho_{\delta \theta} & \rho_{\varepsilon \theta} & \sigma_{\theta}^{2}
\end{array}\right)\right)
$$


If all selection operates through observed covariates, the two equations may be estimated only by using data about individuals who still went to church at 13 . However, if there is correlation between $\delta, \varepsilon$ and $\theta$, estimations made using only this sub-sample produce biased coefficient estimates, due to a possible self selection-mechanism.

Each $y(t)$ denotes a piecewise linear Gompertz function which captures the effect of time on risk. These functions are used to approximate continuous functions, and are composed of functions that are linear within each interval. These linear functions are connected at knots given a priori: piecewise linear Gompertz functions are therefore also continuous functions. This kind of baseline allows for a variety of patterns of the duration dependence in the hazard function (Lillard and Waite, 1993; Baizán et al., 2003). In this analysis, the knots are placed at ages 13, 15, 17, 19 and 25. Ages 13 and 25 were the limit ages in our model, corresponding respectively to duration 0 and to the maximum possible duration in our data. The other knots were placed at ages 15, 17 and 19 (age 20 for discontinuing church attendance), after several experiments, in order to maximise the significance and slope variation of each spline segment, as Lillard and Panis (2000) suggest. Knots were placed at the same ages in the models for males and females, as we found no extremely significant differences.

$\left\{x_{i j}\right\}$ denotes time-constant covariates. $\left\{w_{i k}(\cdot)\right\}$ are time-varying covariates.

Random variables $\delta, \varepsilon$, and $\theta$ capture unobserved heterogeneity, and are assumed to have joint trivariate normal distribution ( $\rho_{\mathrm{hk}}$ is the correlation between the unobserved heterogeneity terms of the equations). The selection equation is a probit equation which requires its unobserved heterogeneity component $\theta$ to have predetermined unit variance.

Model estimation was performed using full-information maximum likelihood, as implemented in the aML 1.04 package (Lillard and Panis, 2000). The t-statistics are based on the BHHH procedure (Berndt et al., 1974).

\section{....and its results}

In the first step (model 1 in table 8), we performed two separate analyses of the two processes (first sexual intercourse, FSI, and discontinued church attendance, DCA), without taking into account unobserved heterogeneity or the correlation between the parallel processes. We found a positive and significant effect of the time-varying covariate DCA on the FSI process, and vice versa. These results are consistent with the H1 ("religiosity effect") and H2 ("adaptation effect") hypotheses. Subsequently, we added random effects to control for unobserved heterogeneity, without considering the correlation between the two processes (extensive results not shown). The parameter representing unobserved heterogeneity, $\sigma$, was highly significant in both equations. 
However, it was definitely greater on the process of DCA ( $\sigma=2.15$ for males, 2.32 for females) than on the transition process to FSI ( $\sigma=0.56$ for males, 0.32 for females $)^{12}$. Accordingly, by including unobserved heterogeneity, there are greater consequences on the effect of FSI on DCA (the "adaptation effect", in relation to model 1, goes from 1.64 to 2.54 for males and from 1.79 to 2.90 for females) than on the effect of DCA on FSI (the "religiosity effect", in relation to model 1, goes from 1.76 to 1.83 for males and from 1.81 to 1.85 for females).

The next step was to add the correlation between the two processes, thus creating a system of two simultaneous equations, taking unobserved heterogeneity into account (model 2 in table 8 ). We obtained a negative correlation $(-0.28$ for males, -0.56 for females), meaning that, among the common latent factors, some factors which act in opposite directions on the two processes prevail (i.e., they support a conciliation between sexual experience and religious participation). ${ }^{13}$ When the correlation between the two processes is considered, the mutual positive effect between FSI and DCA grows considerably (compare model 1 and 2).

We have then examined the possible selection mechanism - due to the fact that the analysis was carried out only on the subsample of individuals attending church at 13 years old - by resorting to a probit model (Heckman, 1979). A multiprocess model was obtained, in which the parallel processes of DCA and FSI were analysed conditional upon attending Mass at 13. We initially estimated two separate multiprocess models, one for DCA and one for FSI. For Italian students, we found a significant correlation only between the selection equation and the process of DCA on the male population (analytical results not shown).

The final model (model 3 in table 8) is a multiprocess model made up of three simultaneously estimated equations: a probit regression for the selection mechanism and two interdependent hazard regressions for DCA and FSI. Since in a previous model we found no evidence of a selection mechanism acting on FSI, in order to avoid identification problems in such a complex model, we decided to constrain the correlation between the probit equation and the hazard equation on FSI to zero. We found that, once we had accounted for the correlation between DCA and FSI, the selection effect proved to be negligible. As a consequence, the results obtained (model 3 in table 8 ) were very similar to those obtained in model 2 in table 8 .

12 The fact that unobserved heterogeneity is lower on FSI than on DCA suggests that the covariates included in the model ("observed heterogeneity") have more explanatory power on FSI than on DCA. In particular, the time-varying covariate "Couple relationship" is strongly connected with FSI. If we exclude this covariate from the model, the parameter representing unobserved heterogeneity greatly increases in the equation on FSI.

13 The aim of this paper was to estimate correctly a measure of the mutual relationship between FSI and DCA, net of potential (observed and unobserved) sources of spuriousness. Nevertheless, it will be interesting, in future research, to go more deeply into a study of the causal mechanisms linking the two processes, including the (latent) factors supporting a conciliation between sexual experience and religious habits (on the basis of the negative correlation between the unobserved heterogeneity of the two processes). 
In all models examined here, we found a positive, strong effect of DCA on FSI and vice versa. Therefore, our data provide empirical evidence of both a "religiosity effect" (H1) and an "adaptation effect" (H2) in Italian university students.

Lastly, we would like to comment briefly on the results obtained for the other covariates, although the effects are not directly relevant for our analysis, being included in the model only as control factors. Parent's church attendance showed a significant effect (in the expected direction) only on the (statistical) risk of DCA, but not on the risk of FSI. Living in the south of Italy had a protective effect on both the risk of DCA and FSI for females, whereas it increases the risk of DCA for males. This reflects a gender difference in religious participation in the south (see Rizzi, 2004).

Having highly educated parents had a positive effect on both processes, but was only significant on FSI. Being in a couple relationship had a strong positive impact on FSI, and a less strong but still significant impact on DCA. 
Caltabiano, Dalla Zuanna \& Rosina: Sexual debut and church attendance in Italy

Table 8: Multiprocess models on risk of first intercourse and risk of discontinuing church attendance. Italian university students attending church at $\mathbf{1 3}$ years old.

\begin{tabular}{|c|c|c|c|c|c|c|}
\hline \multirow{3}{*}{ Covariates } & \multicolumn{6}{|c|}{ Relative risks } \\
\hline & \multicolumn{3}{|c|}{ Males } & \multicolumn{3}{|c|}{ Females } \\
\hline & Model 1 & $\overline{\text { Model } 2}$ & Model 3 & Model 1 & Model 2 & Model 3 \\
\hline \multicolumn{7}{|c|}{ HAZARD MODEL FOR FIRST SEXUAL INTERCOURSE (FSI) } \\
\hline \multicolumn{7}{|l|}{ Spline } \\
\hline Constant & $-6.06^{* * *}$ & $-6.25^{* * *}$ & $-6.25^{* * *}$ & -7.22 *** & $-7.19^{* * *}$ & $-7.18^{* * *}$ \\
\hline Age $13-14$ & $0.88^{* * *}$ & $0.84^{* * *}$ & $0.84^{* * *}$ & $0.93^{* * *}$ & 0.89 *** & $0.89^{* * *}$ \\
\hline Age $15-16$ & $0.47^{\star * *}$ & $0.48^{* * *}$ & $0.48^{* * *}$ & $0.53^{* * *}$ & $0.52^{* * *}$ & $0.52^{* \star *}$ \\
\hline Age $17-18$ & 0.10 & $0.16^{*}$ & $0.16^{* *}$ & $0.12^{\star *}$ & $0.12^{* *}$ & 0.12 ** \\
\hline Age $19+$ & -0.12 * & -0.10 & 0.10 & -0.14 *** & $-0.14^{* * *}$ & -0.14 *** \\
\hline \multicolumn{7}{|c|}{ TIME-CONSTANT COVARIATES } \\
\hline \multicolumn{7}{|c|}{ Attended church at 13} \\
\hline Always & 1.00 & 1.00 & 1.00 & 1.00 & 1.00 & 1.00 \\
\hline Sometimes & 0.98 & 0.93 & 0.93 & 1.05 & 0.99 & 0.99 \\
\hline \multicolumn{7}{|c|}{ Father attended church when child was 13} \\
\hline Weekly & 1.00 & 1.00 & 1.00 & 1.00 & 1.00 & 1.00 \\
\hline Sometimes & 1.16 & 1.15 & 1.15 & 1.13 & 1.09 & 1.09 \\
\hline Never & 1.25 & 1.26 & 1.26 & 1.25 & 1.22 * & 1.22 * \\
\hline \multicolumn{7}{|c|}{ Mother attended church when child was 13} \\
\hline Weekly & 1.00 & 1.00 & 1.00 & 1.00 & 1.00 & 1.00 \\
\hline Sometimes & 0.98 & 0.97 & 0.97 & 0.95 & 0.91 & 0.91 \\
\hline Never & 0.77 & 0.75 & 0.75 & 1.12 & 1.07 & 1.07 \\
\hline \multicolumn{7}{|c|}{ Geographical area of residence } \\
\hline North-centre & 1.00 & 1.00 & 1.00 & 1.00 & 1.00 & 1.00 \\
\hline South & 0.95 & 0.93 & 0.94 & $0.81^{* * *}$ & $0.81^{* * *}$ & $0.81^{* * *}$ \\
\hline Outside Italy & 1.45 & 1.60 & 1.60 & $0.53^{*}$ & 0.55 & 0.55 \\
\hline \multicolumn{7}{|c|}{ Education of father $\mathrm{F}$ and mother $\mathrm{M}$} \\
\hline F low $\mathrm{M}$ low & 1.00 & 1.00 & 1.00 & 1.00 & 1.00 & 1.00 \\
\hline $\mathrm{F}$ high $\mathrm{M}$ low & 1.02 & 1.02 & 1.02 & 1.20 * & 1.20 * & 1.20 * \\
\hline F low M high & 1.06 & 1.04 & 1.04 & 1.30 ** & 1.30 ** & 1.30 ** \\
\hline $\mathrm{F}$ high $\mathrm{M}$ high & $1.18^{*}$ & $1.21 *$ & 1.21 * & $1.14^{*}$ & $1.13^{*}$ & $1.13^{*}$ \\
\hline \multicolumn{7}{|c|}{ TIME-VARYING COVARIATES } \\
\hline \multicolumn{7}{|c|}{ Couple relationship } \\
\hline Never & 1.00 & 1.00 & 1.00 & 1.00 & 1.00 & 1.00 \\
\hline Yes & $5.07^{* * *}$ & $5.64^{* * *}$ & $5.64^{* * *}$ & $11.27^{* * *}$ & $11.39^{* \star *}$ & $11.38^{* * *}$ \\
\hline \multicolumn{7}{|c|}{ Stopped church attendance } \\
\hline No & 1.00 & 1.00 & 1.00 & 1.00 & 1.00 & 1.00 \\
\hline Yes & $1.76^{* * *}$ & $2.32 * * *$ & $2.28^{* * *}$ & $1.81^{* * *}$ & $2.31^{* * *}$ & $2.33^{* \star *}$ \\
\hline
\end{tabular}

${ }^{a}$ Set at zero 
Table 8: (Continued)

\begin{tabular}{|c|c|c|c|c|c|c|}
\hline \multirow{3}{*}{ Covariates } & \multicolumn{6}{|c|}{ Relative risks } \\
\hline & \multicolumn{3}{|c|}{ Males } & \multicolumn{3}{|c|}{ Females } \\
\hline & Model 1 & $\overline{\text { Model } 2}$ & Model 3 & Model 1 & Model 2 & Model 3 \\
\hline \multicolumn{7}{|c|}{ HAZARD MODEL FOR DISCONTINUING CHURCH ATTENDANCE (DCA) } \\
\hline \multicolumn{7}{|l|}{ Spline } \\
\hline Constant & -4.39 *** & $-10.58^{* * *}$ & $-10.98^{* * *}$ & -4.18 *** & $-9.18^{* * *}$ & $-9.17^{* * *}$ \\
\hline Age 13-14 & 0.78 *** & $2.27^{* * *}$ & $2.35^{* * *}$ & $0.55^{* * *}$ & $1.68^{* * *}$ & $1.67^{* * *}$ \\
\hline Age $15-17$ & 0.03 & $0.71^{* * *}$ & $0.75^{* \star *}$ & $-0.11^{\star \star *}$ & $0.37^{* *}$ & 0.36 ** \\
\hline Age $18-19$ & -0.24 ** & 0.11 & 0.12 & -0.05 & 0.16 & 0.16 \\
\hline Age $20+$ & $-0.57^{* * *}$ & -0.46 ** & $-0.45^{* *}$ & $-0.47^{* * *}$ & $-0.35^{* *}$ & $-0.35^{* *}$ \\
\hline \multicolumn{7}{|c|}{ TIME-CONSTANT COVARIATES } \\
\hline \multicolumn{7}{|c|}{ Attended church at 13} \\
\hline Always & 1.00 & 1.00 & 1.00 & 1.00 & 1.00 & 1.00 \\
\hline Sometimes & $2.05^{* * *}$ & $9.81^{* * *}$ & $10.41^{* * *}$ & $1.98^{* \star *}$ & $8.47^{\star \star *}$ & $8.39^{* \star *}$ \\
\hline \multicolumn{7}{|c|}{ Father attended church when child was 13} \\
\hline Weekly & 1.00 & 1.00 & 1.00 & 1.00 & 1.00 & 1.00 \\
\hline Sometimes & $1.56^{* * *}$ & $3.19^{* * *}$ & $3.24^{* * *}$ & $1.43^{* * *}$ & $2.31^{* * *}$ & 2.29 *** \\
\hline Never & $1.82^{* * *}$ & $6.05^{* * *}$ & $5.88^{* * *}$ & $1.59^{* * *}$ & $2.88^{* * *}$ & $2.77^{* *}$ \\
\hline \multicolumn{7}{|c|}{ Mother attended church when child was 13} \\
\hline Weekly & 1.00 & 1.00 & 1.00 & 1.00 & 1.00 & 1.00 \\
\hline Sometimes & $1.25^{* *}$ & $1.84^{\star *}$ & 1.77 & $1.74^{* * *}$ & $3.57^{* * *}$ & 3.34 ** \\
\hline Never & $1.47^{* *}$ & 2.61 * & 2.38 & $1.90^{* * *}$ & 5.59 *** & 4.91 \\
\hline \multicolumn{7}{|c|}{ Geographical area of residence } \\
\hline North-centre & 1.00 & 1.00 & 1.00 & 1.00 & 1.00 & 1.00 \\
\hline South & $1.25^{* * *}$ & 2.54 *** & $2.64^{* * *}$ & $0.88^{* *}$ & 0.80 & 0.81 \\
\hline Outside Italy & 0.86 & 0.46 & 0.44 & 1.01 & 0.83 & 0.79 \\
\hline \multicolumn{7}{|c|}{ Education of father $\mathrm{F}$ and mother $\mathrm{M}$} \\
\hline F low M low & 1.00 & 1.00 & 1.00 & 1.00 & 1.00 & 1.00 \\
\hline $\mathrm{F}$ high $\quad \mathrm{M}$ low & 0.99 & 0.87 & 0.88 & 0.93 & 0.96 & 0.94 \\
\hline F low $\quad M$ high & 0.96 & 0.96 & 0.94 & 0.98 & 1.00 & 1.00 \\
\hline $\mathrm{F}$ high $\mathrm{M}$ high & 1.13 & 1.32 & 1.34 & 1.09 & 1.32 & 1.29 \\
\hline \multicolumn{7}{|c|}{ TIME-VARYING COVARIATES } \\
\hline \multicolumn{7}{|l|}{ Couple relationship } \\
\hline Never & 1.00 & 1.00 & 1.00 & 1.00 & 1.00 & 1.00 \\
\hline Yes & $1.19^{* *}$ & 1.46 * & $1.48^{* *}$ & $1.51^{* * *}$ & $1.90^{* * *}$ & $1.90^{* \star *}$ \\
\hline \multicolumn{7}{|l|}{ Sexual intercourse } \\
\hline Never & 1.00 & 1.00 & 1.00 & 1.00 & 1.00 & 1.00 \\
\hline Yes & $1.64^{* * *}$ & $3.93^{* * *}$ & $3.97^{* * *}$ & $1.79^{* * *}$ & $3.89^{* * *}$ & $3.95^{\star * *}$ \\
\hline
\end{tabular}

a Set at zero 
Caltabiano, Dalla Zuanna \& Rosina: Sexual debut and church attendance in Italy

Table 8: (Continued)

\begin{tabular}{|c|c|c|c|c|c|c|}
\hline \multirow{3}{*}{ Covariates } & \multicolumn{6}{|c|}{ Relative risks } \\
\hline & \multicolumn{3}{|c|}{ Males } & \multicolumn{3}{|c|}{ Females } \\
\hline & Model 1 & Model 2 & Model 3 & Model 1 & Model 2 & Model 3 \\
\hline \multicolumn{7}{|c|}{ PROBIT MODEL (SELECTION) FOR CHURCH ATTENDANCE AT 13 YEARS OLD } \\
\hline Constant & - & - & $-1.71^{* \star *}$ & - & - & -2.36 *** \\
\hline \multicolumn{7}{|l|}{ TIME-CONSTANT COVARIATES } \\
\hline \multicolumn{7}{|c|}{ Father attended church when child was 13} \\
\hline Weekly & - & - & 1.00 & - & - & 1.00 \\
\hline Sometimes & - & - & $1.57^{\star \star *}$ & - & - & 1.18 \\
\hline Never & - & - & $3.37^{* * *}$ & - & - & $1.73^{* * *}$ \\
\hline \multicolumn{7}{|c|}{ Mother attended church when child was 13} \\
\hline Weekly & - & - & 1.00 & - & - & 1.00 \\
\hline Sometimes & - & - & $2.04^{\star * \star}$ & - & - & 3.26 *** \\
\hline Never & - & - & $4.44^{* \star *}$ & - & - & $5.83^{* \star *}$ \\
\hline \multicolumn{7}{|l|}{ Residence during high school } \\
\hline North-centre & - & - & 1.00 & - & - & 1.00 \\
\hline South & - & - & $1.23^{\text {** }}$ & - & - & 0.80 ** \\
\hline Outside Italy & - & - & 1.86 & - & - & 1.64 ** \\
\hline \multicolumn{7}{|l|}{ Education of father $\mathrm{F}$ and mother $\mathrm{M}$} \\
\hline F low M low & - & - & 1.00 & - & - & 1.00 \\
\hline F high $\mathrm{M}$ low & - & - & $0.77^{*}$ & - & - & 1.25 \\
\hline F low $\mathrm{M}$ high & - & - & 0.86 & - & - & 1.09 \\
\hline$F$ high $M$ high & - & - & 1.05 & - & - & $1.48^{* * *}$ \\
\hline \multicolumn{7}{|c|}{ UNOBSERVED HETEROGENEITY AND CORRELATION } \\
\hline Unobserved heterogeneity for FSI & - & $0.58^{* \star *}$ & $0.58^{* * *}$ & - & 0.29 & 0.29 \\
\hline Unobserved heterogeneity for DCA & - & $2.83^{* * *}$ & $2.95^{* \star *}$ & - & $2.54^{* \star *}$ & $2.54 * \star *$ \\
\hline Correlation: FSI \& DCA (r1) & - & -0.28 ** & $-0.26^{* *}$ & - & -0.56 & -0.57 \\
\hline $\begin{array}{l}\text { Correlation: FSI \& selection } \\
\text { (probit model) }(r 2)\end{array}$ & - & - & $0.00^{\mathrm{a}}$ & - & - & $0.00^{\mathrm{a}}$ \\
\hline $\begin{array}{l}\text { Correlation: DCA \& selection } \\
\text { (probit model }(r 3)\end{array}$ & - & - & -0.11 & - & - & -0.12 \\
\hline
\end{tabular}

a Set at zero 